\title{
XVII
}

\section{O IMPACTO DA PANDEMIA NO TRABALHO DOS ASSISTENTES SOCIAIS NA ATENÇÃO PSICOSSOCIAL E PROTEÇÃO SOCIAL*}

Míriam Thais Guterres Dias Vanessa Maria Panozzo Brandão

Aline Mattos Fuzinatto

Bruno Camilo Marchi Pereira

\section{Introdução}

Discutir sobre o impacto da pandemia no trabalho de assistentes sociais na atenção psicossocial e proteção social ${ }^{1}$ se faz necessário pela constatação de que a pandemia provocada pelo novo coronavírus está alterando profundamente a sociedade, nos aspectos políticos, econômicos e sociais, e notadamente, afetando os modos de vida da população em âmbito mundial. Consequentemente, impacta o trabalho dos profissionais da saúde mental e da assistência social. A partir de revisão de literatura e de discussão de situações vividas por assistentes sociais em um Centro de Referência de Assistência Social (CRAS) e um Centro de Atenção Psicossocial Álcool e Drogas (CAPSad), se objetiva refletir criticamente sobre as requisições postas a estes profissionais no cotidiano da atenção à população, em especial àqueles em sofrimento psíquico e os com uso problemático de drogas.

Considerando o necessário distanciamento social para provocar algum controle na propagação do vírus, e o fato de a saúde e a assistência social serem políticas públicas sensíveis às necessidades e demandas da população, se torna relevante o debate e reflexão so-

\footnotetext{
*DOI- 10.29388/978-65-86678-44-4-0-f.431-450

${ }^{1}$ Este capítulo faz parte da discussão teórica de pesquisa em andamento realizada pelas/o autoras/o.
} 
bre o trabalho de assistentes sociais com a população que vive as consequências da histórica desigualdade social no país, e com os agravamentos em decorrência da pandemia do novo coronavírus.

A COVID-19 é uma doença causada pelo coronavírus que em 30 de janeiro de 2020, a Organização Mundial da Saúde (OMS) a declarou como uma emergência de saúde pública global e, em 11 de março de 2020, passou a ser considerada uma pandemia (OPAS, 2020). Os órgãos sanitários informam que os casos não detectados e assintomáticos são os maiores responsáveis pela elevada taxa de transmissão COVID-19 e por isso foi recomendado no mundo todo o isolamento social como forma de prevenção à doença, visando diminuir a necessidade de internações e de mortes. (BARRETO et al., 2020)

Esta pandemia evidenciou a existência e a persistência da desigualdade social no âmbito mundial, que tende a se acentuar em um sistema no qual a prioridade tem sido as políticas econômicas. Para Konicz (2020) o "sistema capitalista mundial está a entrar na crise mais grave da sua história, cujas consequências - se não forem ultrapassadas rapidamente - podem deixar na sombra até mesmo a década de 1930". Ainda não é possível antever como estarão as sociedades no mundo após esta pandemia passar, mas os prognósticos são preocupantes, e, portanto, muitas pesquisas precisam se realizar para contribuírem com novos conhecimentos sobre a realidade deste momento.

No contexto brasileiro, segundo o Painel Coronavírus, (BRASIL, 2020 a), até o dia 08/09/2020 foram notificados 4.147 .794 casos confirmados de COVID-19 e 126.960 óbitos. Os dados configuram um índice de letalidade de 3,1\% no país. As medidas de restrição social são relevantes para conter a pandemia, mas em país com subfinanciamento das políticas de proteção social, como o Brasil, consequências drásticas para a população em situação mais vulnerável são esperadas. Pois o conhecimento existente é de que os sistemas de saúde e proteção social são fundamentais para a garantia de direitos e condições de vida da população.

Estudo realizado sobre o efeito da recessão econômica e o impacto dos gastos com saúde e proteção social na mortalidade de adultos de 5.565 municípios brasileiros (HONE et al., 2020) revelou o 
aumento de mortes em cidades onde o investimento com a assistência social e a saúde foi menor, e constado que a recessão econômica brasileira contribuiu para o aumento da mortalidade no país. Este estudo foi feito a partir de dados do Ministério da Saúde, do Ministério de Desenvolvimento Social, do IBGE e do Sistema de Informações sobre Orçamentos Públicos em Saúde (SIOPS), de 2012 a 2017, quando os pesquisadores verificaram a relação entre recessão, desemprego e mortalidade nos municípios brasileiros.

Este contexto produz desafios para o trabalho nos sistemas de proteção social no SUAS e da atenção psicossocial no SUS, quanto ao que a realidade tem demandado aos profissionais das diferentes áreas nas políticas sociais. Isto porque, "as políticas públicas de Saúde e Assistência Social no Brasil têm peculiaridades e sofrem determinações do contexto de ajuste estrutural econômico, sob orientação das agências internacionais, como focalização e mercantilização dos bens sociais e redução do gasto público, repercutindo notadamente nas agendas das políticas sociais e, consequentemente, na vida da população" (DIAS, 2018, p. 23).

Os ataques à classe trabalhadora, típico do sistema econômico capitalista, aprofundado no contexto da pandemia, faz com que as políticas sociais percam a condição de serem expressões de direitos. Modifica-se o padrão de políticas sociais universais e passa-se a ter políticas sociais sem direitos sociais. (VIEIRA, 1997)

O debate proposto por este capítulo será realizado nos tópicos sobre as expressões da questão social agudizadas pela pandemia da COVID-19 e sobre o impacto da crise sanitária no trabalho de assistentes sociais na atenção psicossocial e proteção social.

\section{As expressões da questão social agudizadas pela pande- mia da COVID-19}

O quadro do acirramento da desigualdade social se expressa com alguns indicadores: solicitações de seguro-desemprego no mês de maio de 2020, foram $53 \%$ superior à quantidade de pedidos realizados no mesmo período do ano anterior; a informalidade já atinge cerca de $40 \%$ da força de trabalho brasileira; os 107 milhões de pedi- 
dos de auxílio emergencial realizados deu visibilidade aos trabalhadores informais no país (PRAUN, 2020). Dados do IBGE (2020) apontam que o segundo trimestre de 2020 registrou recorde com a redução de 9,6\% no número de pessoas ocupadas no Brasil, com 8,9 milhões de pessoas que perderam seus postos de trabalho de abril a junho, comparando ao período de janeiro a março, e a população ocupada ficou em 83,3 milhões, sendo o menor nível da série histórica iniciada em 2012. Se comparado com o mesmo período de 2019 a queda foi de $10,7 \%$. E o desemprego subiu para $13,3 \%$ no 20 trimestre, com a redução recorde de ocupados.

A população que busca os serviços de proteção social sofre o impacto da redução da renda com a perda do vínculo formal de trabalho em decorrência da pandemia, ou não tem mais acesso as parcelas do seguro-desemprego, e, não atendem aos critérios para obterem o auxílio emergencial, sem perspectivas de se realocarem no mercado de trabalho em decorrência do desemprego. Esta situação também afeta as condições de moradia, pois diferentes gerações da mesma família que viviam em casas separadas voltaram a morar juntos. Como diz Harvey (2020, p. 06) "o progresso da COVID-19 exibe todas as características de uma pandemia de classe, de gênero e de raça", pois as maiores vítimas são:

[...] moradores da periferia e dos subúrbios, pessoas em privação de liberdade e asilamento, pessoas dependentes do transporte púbico, trabalhadores que lidam com outras pessoas - comerciários, autônomos, profissionais de saúde - enfim, a maioria da população brasileira. Tendo em vista a desigualdade crônica do nosso país, a pandemia tende a vitimar os mais pobres, dentre os quais os afrodescentes são a maioria (CAMPOS, 2020, p. 4).

Estes brasileiros em maior sofrimento decorrente da pandemia são uma evidência do acirramento das desigualdades sociais no país, o que implica em uma análise da realidade social a partir da perspectiva da totalidade, para além das condições de saúde da população. Esta compreensão se pauta em uma posição ético-política em relação aos desafios presentes no cotidiano profissional, considerando-se ainda as presentes posições e análises conservadoras da vida social. Estas se inspiram em "um modo de vida do passado, que 
é resgatado e proposto como uma maneira de interpretar o presente como conteúdo de um programa viável para a sociedade capitalista" (IAMAMOTO, 1992, p. 22), sendo um pensamento restaurador, preservador, e que reforça a autoridade moral (YAZBEK, 2018).

O governo brasileiro vem adotando medidas extremamente conservadoras na direção da perda de direitos e das liberdades a partir dos contrassensos apresentados na "relação aos direitos humanos, a subalternização da mulher, a negação da diversidade humana, a imposição de padrões familiares, religiosos, de pensamento e o ataque as liberdades democráticas" (PRATES, REIDEL, ORTH, 2020, p. 147). Estas posições contribuem para que a população se distancie cada vez mais de projeções democráticas considerando a criminalização das manifestações populares.

É nesse contexto que o conservadorismo tem encontrado espaço para se reatualizar, apoiando-se em mitos, motivando atitudes autoritárias, discriminatórias e irracionalistas, comportamentos e ideias valorizadoras da hierarquia, das normas institucionalizadas, da moral tradicional, da ordem e da autoridade. Uma das expressões dessa ideologia é a reprodução do medo social (BARROCO, 2011, p. 06).

A conjuntura é de reestruturação produtiva e redução do Estado, de precarização das condições de vida e de trabalho da classe trabalhadora, segmento populacional que em tempos de isolamento social estará mais vulnerável para garantir sua sobrevivência (MATOS, 2020). Este é o principal público atendido no SUS e SUAS, por sofrerem um maior impacto também com o agravamento da situação econômica na pandemia, intensificada com a vigência da Medida Provisória 927 (BRASIL, 2020b). Pois,

[...] intervenções devem ser postas em prática, que devem incluir: a prestação de serviços universais de saúde e sociais, bem como intervenções públicas para garantia do trabalho e direitos sociais da população, devido à deterioração da mercado de trabalho criado pela pandemia (NAVARRO, 2020, p. 274) [tradução das/o autores]

Vários segmentos da população estão sendo afetados de forma contundente, como os em situação de sua, os catadores de materiais recicláveis, os em privação de liberdade. Mas se destaca a situa- 
ção das mulheres trabalhadoras domésticas, pois Pinheiro, Tokarski e Vasconcelos (2020, p. 9), informam que são "cerca de 6 milhões de mulheres no Brasil, o que corresponde a quase $15 \%$ das trabalhadoras ocupadas ( $10 \%$ das brancas e $18,6 \%$ das negras)", e fazem parte do grupo de apenas $28 \%$ dos/as trabalhadores/as domésticos/as do país com carteira de trabalho assinada. Ou seja, a informalidade continua sendo uma marca destes/as trabalhadores/as, alijadas dos direitos trabalhistas e previdenciários (ainda) existentes no país. "Por um lado, os corpos submetidos ao trabalho flexibilizado, intensificado, mal remunerado, destituído de direitos. Por outro, os 'sobrantes', contingente que já não consegue retornar ao mercado de trabalho. Descartáveis" (PRAUN, 2020, p. 5)

Os trabalhadores da saúde e da assistência social se encontram na linha de frente na situação da pandemia, com a falta de equipamentos de proteção individual, férias previstas suspensas, sujeitos ao impacto sobre a saúde mental que tende a aumentar significativamente em contextos de emergências de saúde pública, sobretudo quando as condições de biossegurança no trabalho não estão garantidas (CARVALHO, 2020).

Estas condições precarizadas de trabalho, somada à diminuição dos recursos investidos nessas políticas, incidem diretamente nos processos de trabalho ${ }^{2}$ de assistentes sociais na atenção psicossocial e proteção social que atendem e/ou acompanham pessoas em sofrimento psíquico e em uso problemático de drogas.

Conforme demonstrado claramente por todo um conjunto de evidências sobre os determinantes sociais da saúde mental, o maior risco de desenvolver sofrimento mental grave e duradouro recairá sobre aqueles já afetados pela desigualdade social, e isso será agravado pela crise atual e suas consequências (ROSE et al., p. 4) [tradução das/o autoras/o]

\footnotetext{
${ }^{2}$ Usa-se a expressão processos de trabalho a partir da conceituação de lamamoto (2005, p. 106), que retoma a inexistência de um processo de trabalho do assistente social e o recurso heurístico à noção de inserção do assistente social em processos de trabalho, pois "não se trata de um mesmo processo de trabalho social e sim de processos de trabalho nos quais se inserem os assistente sociais" O desafio está em "apreender as particularidades dos processos de trabalho, que em circunstâncias diversas, vão atribuindo feições limites e possibilidades no exercício da profissão".
} 
Há uma estimativa de que, durante uma pandemia, entre um terço e metade da população poderá ter sofrimento psíquico, considerando a sua magnitude e "o grau de vulnerabilidade em que a pessoa se encontra no momento. Entretanto, é importante destacar que nem todos os problemas psicológicos e sociais apresentados poderão ser qualificados como doenças" (FIOCRUZ, 2020, p. 02). No entanto, devido a magnitude do problema,

[...] a grande maioria das necessidades de saúde mental permanece não endereçada. A resposta é dificultada pela falta de investimento na promoção da saúde mental, prevenção e cuidados antes da pandemia. [...] que precisa ser corrigido sem demora para reduzir imenso sofrimento entre centenas de milhões de pessoas. (ONU, 2020, p. 03) [tradução das/o autores]

Mais especificamente sobre o uso problemático de drogas, o III Levantamento Nacional sobre o Uso de Drogas pela População Brasileira realizado pela Fundação Instituto Oswaldo Cruz - FIOCRUZ (2017) revelou que 3,2\% dos brasileiros usaram substâncias ilícitas nos 12 meses anteriores a pesquisa, cerca de 4,9 milhões de pessoas. Esse consumo é maior entre os jovens, 7,4\% (idades de 18 a 24 anos), seguido pelos homens, $5 \%$ da população, e de 1,5\% entre as mulheres. A substância ilícita mais consumida é a maconha, apontada por $7,7 \%$ dos brasileiros entre 12 e 65 anos, e a segunda, é a cocaína em pó, referida por 3,1\% dos pesquisados. Quanto ao uso de crack, o estudo estimou que 1,4 milhões de pessoas ( $0,9 \%$ da população) entre 12 e 65 anos o consumiram alguma vez na vida, sendo $1,4 \%$ homens e $0,4 \%$ mulheres.

No entanto, considerando que o levantamento domiciliar não alcança pessoas que são usuárias e não se encontram em domicílios, estima-se que esse número seja maior, a considerar que os usuários de crack compõem uma população majoritariamente marginalizada, que vive em situação de rua, como revelado na Pesquisa Nacional do Uso de Crack (FIOCRUZ, 2014), que apontou o percentual de 2,9\% da população, sendo o consumo dessa substância um fenômeno do espaço público.

Das substâncias lícitas, a pesquisa de 2017 revelou que 13,6\% $(20,8$ milhões) dos brasileiros declarou ter fumado cigarro no último 
mês. O consumo de medicações de uso controlado sem prescrição médica foi de $0,6 \%$ ara analgésicos opiáceos e $0,4 \%$ para tranquilizantes benzodiazepínicos. $\mathrm{O}$ uso de álcool tem números expressivos na referida pesquisa, pois 46 milhões $(30,1 \%)$ referiram ter consumido ao menos uma dose nos 30 dias anteriores, e desses 2,3 milhões apresentaram critérios para dependência do álcool no ano anterior ao levantamento, o que equivale a um percentual de $2,5 \%$ à $4,1 \%$ nas faixas etárias pesquisadas, de 12 à 65 anos, sendo que não houve diferença estatisticamente significativa entre elas.

Esta contextualização e discussão sobre as expressões da questão social agudizadas pela pandemia da COVID-19 se constituem a matéria sobre a qual o trabalho de assistentes sociais se realizará.

\section{O impacto da crise sanitária no trabalho de assistentes so- ciais na atenção psicossocial e proteção social}

Brevemente é importante ressaltar que as políticas de saúde e de assistência social têm sido sucateadas ao longo do tempo, o que inviabilizou, até o momento, o cumprimento pleno dos seus princípios e diretrizes como políticas de alcance dos direitos sociais dos brasileiros. A saúde vem a décadas com subfinanciamento e desde 2016, com desfinanciamento do SUS a partir do congelamento de teto de gastos imposto pela EC-95 em 2016 (FRENTE PELA VIDA, 2020). A assistência social teve corte recentes nos repasses federais "superior a 75\%, sem reposição, tornando o funcionamento desse sistema público quase inviabilizado, levando ao extremo de fechamento de serviços e demissão dos profissionais da área" (LOPES; RIZZOTTI, 2020, p. 136).

Esta realidade associada a pandemia da COVID-19 aprofunda e complexifica demandas, requisições e atribuições dos/as assistentes sociais, principalmente no âmbito do SUS e do SUAS, políticas que empregam aproximadamente $90 \%$ de assistentes sociais no Brasil (PRATES, REIDEL, ORTH, 2020), trazendo novos desafios para a afirmação do Projeto Ético-Político em um momento histórico pandêmico e com inúmeras restrições sanitárias. 
A condição primeira para se enfrentar uma pandemia de tal dimensão no Brasil, seria assegurar, constitucionalmente, a indissociabilidade entre as medidas de restrição à população (reguladas pela Saúde) e as medidas de proteção social, pelo tempo necessário, concebendo um sentido de segurança nacional no país (LOPES; RIZZOTTI, 2020, p. 133).

A peculiaridade entre as políticas setoriais de saúde e assistência social revela a necessidade e uma exigência de articulação das políticas, superando uma prática setorializada à população que requer respostas concretas às suas necessidades. Mas para tanto um trabalho precisa ser desencadeado e sustentado, pois a intersetorialidade é "entendida como a articulação de saberes e experiências no planejamento, a realização e avaliação de ações, com o objetivo de alcançar resultados integrados em situações complexas" (INOJOSA, 1998, p. 43).

Existe uma dificuldade na realização da intersetorialidade sendo, portanto, um forte desafio para o alcance da desejada integralidade na atenção à saúde e na proteção social dos brasileiros. Em pesquisa realizada com profissionais da saúde e da assistência social sobre a gestão dos serviços para a atenção ao usuário de drogas (DIAS, 2017), foi constatado o alto percentual da procura de outras políticas setoriais: dos serviços SUS, 93,33\% procuram os do SUAS; vice-versa, em 90,48\%. Contudo, não há uma ação articulada entre os setores, pois o trabalho realizado é pontual para cada caso de atendimento de usuário, mesmo sendo esta uma necessidade corriqueira nos serviços. Mas, é possível a execução dos processos de trabalho entre os profissionais das políticas setoriais, sendo um caminho profícuo a ser construído no cotidiano dos trabalhadores, dando sentido às premissas das políticas de saúde e de assistência social, o que viabiliza a perspectiva do acesso aos direitos sociais.

Ao analisar os processos de trabalho, não se perde a dimensão da totalidade dos processos de precarização advindos das transformações do mundo do trabalho construídos historicamente, principalmente neste momento de pandemia, que inclusive, demarca de forma trágica a perda dos direitos sociais da classe trabalhadora. Este locus diz respeito a uma subordinação no campo das políticas sociais ao econômico, refletindo diretamente naquilo que compõe este cam- 
po, impactando no seu conceito, nas condições e relações de trabaIho entre os trabalhadores e, não distanciada disso, a população atendida.

As novas formas de acumulação e flexibilização dos mercados, das relações de trabalho e dos direitos expressam a ampla e profunda transformação estrutural do trabalho assalariado, com rebatimentos na materialidade e na subjetividade da classe trabalhadora. Com isso, são experimentamos a perda de direitos e a insegurança do presente e do futuro, o que agrava a fragmentação e a fragilização das estratégias de resistência e de organização coletivas (RAICHELIS, 2018, p. 07).

Partindo-se da perspectiva materialista e dialética, o homem, ao se relacionar com a natureza produz sua consciência que, para ele, está além das necessidades biológicas de sobrevivência, é mediada pelo trabalho, na qual propicia relações com outros homens, bem como, criam-se novas necessidades, que são próprias da sociabilidade humana. "São os homens, desenvolvendo sua produção material e suas relações materiais, transformam, com a realidade que Ihes é própria, seu pensamento e os produtos do seu pensamento" (MARX; ENGELS, 2002, p. 200), pois é a vida que determina a consciência.

É nessa inter-relação que se encontra o movimento do real, da possibilidade de o homem se fazer como matéria, da natureza que se expressa e de seu conteúdo sensível (PANOZZO, 2009). Para Marx (1975), é justamente na relação com o real, materializada na natureza, que o homem se estabelece como sujeito, considerando o trabalho como fundamento do processo de objetivação humana. Assim, diz Marx:

É justamente em seu trabalho exercido no mundo objetivo que o homem realmente se comprova como um ente-espécie. $O$ objetivo do trabalho, portanto, é a objetivação da vida como espécie do homem, pois ele se reproduz a si mesmo, apenas intelectualmente, como na consciência, mas ativamente no sentido real, e vê seu próprio reflexo em um mundo por ele construído (MARX, 1975 (I manuscrito), p. 101).

O trabalho sendo uma mediação concreta entre o homem e a natureza, também sofre modificações a partir do processo de produ- 
ção e reprodução das relações sociais, e nesta concepção, daquilo que é permeado pela realidade social no momento histórico. Assim sendo, a contextualização deste momento histórico, é inclusive premissa para a compreensão do cenário posto na relação do capital, dos modos de produção e das condições e relações impostas pelo mundo do trabalho para que seja possível uma interpretação crítica daquilo que se faz das atividades como trabalho.

Neste momento, as expressões da questão social das diferentes parcelas da população que acessam os serviços se aguçam ainda mais, incluindo-se demandas àqueles que sobrevivem neste sistema, e que agora, mais do que nunca, necessitam de respostas coletivas do Estado. Além disso, as consequências desta pandemia têm agravado as condições de trabalho, com o revezamento e plantão dos profissionais, ou, na condição do trabalho remoto; ou, a situação do desemprego e do trabalho desprotegido e em condições de precariedade. Conforme Cavalcante e Predes (2010, p. 8),

\begin{abstract}
A intensificação do desemprego e situação de vulnerabilidade, imbricadas em suas determinações cotidianas, estão agravando a situação dos trabalhadores e de seus familiares, causando rupturas profundas em alguns segmentos sociais, ampliando o grau de miserabilidade e destruindo relações humanas, muitos se transformando em demanda para os profissionais que trabalham na área social.
\end{abstract}

Matos (2020) ao abordar a relação do trabalho particularizado na saúde, mas que se aplica plenamente ao trabalho na assistência social, indica que é importante se estar vigilante para aquilo que é solicitado para os profissionais em suas intervenções, pois o momento vivido é de extrema vulnerabilidade, podendo ser induzidas modificações na conduta ético-política bem como nos fundamentos que se constituem as referências teóricas e técnicas das profissões.

Tanto os serviços da atenção psicossocial como da proteção social vivenciam as restrições impostas pela pandemia, com a interrupção de serviços no funcionamento dos serviços a partir da troca de turnos, revezamentos dos trabalhadores, mudanças nas rotinas e formas de trabalho dos seus profissionais. Essas modificações implicam em novos desafios para o trabalho e para as demandas trazidas pelas pessoas atendidas, que requerem a análise dos processos de 
trabalho instituídos no presente momento, que trará consequências históricas profundas. Aliada às já existentes falta de condições da estrutura física e de pessoal dos serviços, ocorre uma fragilidade nos processos de acompanhamento dos usuários e familiares, pois também foi implantado o atendimento pelo telefone. Situações que vem modificando as demandas das pessoas atendidas, do trabalho e consequentemente da qualidade do serviço prestado, que atinge a possibilidade de realização das premissas das políticas públicas.

Estas mudanças se respaldam na Nota Técnica № 12/2020 do Ministério da Saúde (BRASIL, 2020c), que faz orientações para os gestores e serviços sobre as medidas preventivas, abertura e funcionamento dos serviços de saúde e protocolos de cuidado. Na mesma direção, medidas de proteção são indicadas para a política de assistência social através da Portaria no 337, de 24 de março de 2020 (BRASIL, 2020d).

As recomendações são de que as atividades assistenciais sejam mantidas, com o suporte a pessoas em situação de crise e manejo de agudizações, além do seguimento terapêutico, avaliando a possibilidade de redistribuição de consulta e atendimentos. Sugere suspensão de atividades em grupo e coletivas e a adoção de estratégias de atendimento a distância ou domiciliar, se necessário. Orienta ainda que os atendimentos, reuniões de rede e discussões de casos possam adotar alternativas de comunicação virtual, como por telefone, videochamada e videoconferência. E, para reduzir a exposição dos trabalhadores em saúde, recomenda alterações de escala de trabaIho, atendimentos virtuais e a redução da circulação e aglomeração nos serviços.

Essas modificações impactam diretamente no trabalho de assistentes sociais inseridos nesses espaços que precisam adaptar-se às novas tecnologias no atendimento prestado à população, bem como criar estratégias que visem a garantia de direitos à população que não acessa esses meios tecnológicos, dada as condições de extrema vulnerabilidade, considerando a direção do projeto Ético-Político da profissão. Sobre a orientação de realização de teleatendimento, o Conselho Federal de Serviço Social (CFESS, 2020) publicou nota afirmando que essa modalidade deve ter caráter absolutamente excepcional, considerando a particularidade deste momento. Afirma que de- 
cidindo, com autonomia, por utilização dessa modalidade de atendimento, os/as assistentes sociais devem considerar a qualidade do serviço prestado e a garantia dos preceitos ético profissionais, em especial no que se refere ao sigilo profissional.

Essa excepcionalidade da crise sanitária atinge diretamente o cotidiano de todos os profissionais do serviço social quando ao cumprimento das competências e atribuições estabelecidas pela Lei de Regulamentação da Profissão (Lei no 8.342/1993), pois novas requisições são postas aos profissionais para atenderem as necessidades sociais dos usuários. Conforme aponta Guerra (2016), as requisições têm diferentes interpretações, que podem ser de ordem institucional que representam as próprias instituições, políticas e programas sociais ou também àquelas demandadas pelos usuários. A autora enfatiza que as contradições devem ser desveladas a partir do contexto da realidade institucional e a dos segmentos sociais, sendo necessário superar a aparência dos fenômenos que afetam as condições de vida e de trabalho.

As demandas das classes sociais põem e repõem objetos para o Serviço Social. Estes encontram-se inscritos nas condições sociais das classes e por isso são, de um lado, históricos, transitórios, encerram continuidades e rupturas e, de outro, ou não extrapolam o limite material ou mantêm-se no nível das necessidades imediatas. Tais demandas convertem-se em requisições profissionais, cujo atendimento requer a mobilização de um determinado nível de racionalidade, de uma parte; limitam e determinam as funções profissionais, de outra (GUERRA, 1995, p. 199-200).

Para além das requisições atuais postas ao serviço social, a conformação das demandas atuais diferencia-se, uma vez que a pandemia tem atingido todos os segmentos da população, e é claro evidenciando ainda mais as classes impactadas pela desigualdade social. Neste sentido, o atual contexto, que acirra as expressões da questão social vivenciadas pela população atendida nos serviços de saúde e de assistência social, somado às medidas tomadas para conter a propagação do vírus, que reduziram os atendimentos presenciais realizados nesses espaços, impactaram diretamente na redução da ofertas dos serviços prestados. 
Neste sentido, Prates, Reidel, Orth, (2020, p. 152) chamam a atenção para os processos de politização na execução do trabalho, uma vez que não se pode perder de vista àquilo que é próprio do capitalismo, como por exemplo, "[...] os processos de manipulação e captura da subjetividade [...]" e que as mediações na materialização do trabalho possam realizar "[...] a análise crítica dos dados de realidade, à luz da teoria e da totalidade".

Para tanto, reafirma-se os compromissos Ético-Políticos para a realização de um trabalho profissional, considerando a divisão sociotécnica da sociedade capitalista, com qualidade e em sintonia com a classe trabalhadora.

Os assistentes sociais realizam, assim, uma ação de cunho socioeducativo na prestação de serviços sociais, viabilizando o acesso aos direitos e aos meios de exercê-los, contribuindo para que necessidades e interesses dos sujeitos sociais adquiram visibilidade na cena pública e possam ser reconhecidos, estimulando a organização dos diferentes segmentos dos trabalhadores na defesa e na ampliação dos seus direitos (IAMAMOTO, 2017, p. 23).

\section{Considerações Finais}

A instauração da crise sanitária trouxe impactos severos na vida da população, compondo as diferentes esferas da vida social: na saúde, na economia, no âmbito social e nas relações de trabalho. 0 trabalho remoto, o teletrabalho, a individualização dos processos de trabalho, troca do período de férias, banco de horas, redução de salários, entre outros, colocam de forma mais latentes prejuízos ao trabaIho.

Neste sentido, não se pode afirmar que apenas o momento da pandemia trouxe novas requisições para o trabalho do assistente social. Desde a contrarreforma do Estado que as políticas sociais vêm sofrendo impactos importantes e modificando a realidade da vida dos trabalhadores. Os modelos de gestão vinculados a reestruturação produtiva de uma forma silenciosa modificaram sensivelmente as condições de trabalho, e por sua vez, também a condição de assalariamento. Neste sentido, a pandemia da COVID 19 potencializou as re- 
lações de submissão impostas pelo processo de produção capitalista, só que agora, tirando literalmente a vida da população.

O trabalho do assistente social tem uma direção de extrema importância na realidade social, que assume a construção constante de uma sociedade mais justa e igualitária e ainda a socialização da riqueza produzida. As requisições para o serviço social colocadas no âmbito institucional têm problematizado a própria direção social da profissão, uma vez que, no cotidiano do trabalho, ainda se faz necessária a superação do conservadorismo, identificado desde o movimento de reconceituação e traduzido em diferentes modos de intervenções nas políticas de saúde e assistência social.

\section{Referências}

BARRETO, M. L. et al. O que é urgente e necessário para subsidiar as políticas de enfrentamento da pandemia de COVID-19 no Brasil? Revista Brasileira de Epidemiologia, Rio de Janeiro, v. 23, e200032, 2020. Disponível em: <https://www.scielo.br/pdf/rbepid/v23/19805497-rbepid-23-e200032.pdf>. Acesso em: 15 mai. 2020.

BARROCO, M. L. S. Barbárie e neoconservadorismo: os desafios do projeto ético-político. Serviço Social \& Sociedade, São Paulo, n. 106, p. 205-218, abr./jun. 2011. Disponível em: <https://www.scielo.$\mathrm{br} /$ scielo.php?script=sci_isoref\&pid=S010166282011000200002\&lng=en\&tlng=pt>. Acesso em: 17 abr. 2016.

BRASIL. Ministério da Saúde. Painel Coronavírus. 2020a. Disponível em: <https://covid.saude.gov.br/>. Acesso em: 08 dez. 2020.

. Medida Provisória № 927. Brasília, 22 de março de $2020 \mathrm{~b}$. Disponível em: <http://www.planalto.gov.br/ccivil_03/_ato20192022/2020/Mpv/mpv927.htm>. Acesso em: 20 abr. 2020.

. Ministério da Saúde. Secretaria de Atenção Primária à Saúde. Nota Técnica № 12. 2020c. Disponível em: <http://189.28.128.100/ dab/docs/portaldab/documentos/notatecnica122020CGMADDAPESSAPSMS02abr2020COVID-19.pdf>. Acesso em: 02 set. 2020. 
. Ministério da Cidadania. Portaria no 337, de 24 de março de

2020d. Dispõe acerca de medidas para o enfrentamento da emergência de saúde pública de importância internacional decorrente do coronavírus, COVID-19, no âmbito do Sistema Único de Assistência Social. 2020d. Disponível em: <http://blog.mds.gov.br/redesuas/portariano-337-de-24-de-marco-de-2020/>. Acesso em: 02 set. 2020.

CAMPOS, G. W. S. O pesadelo macabro da COVID-19 no Brasil: entre negacionismos e desvarios. Trabalho, Educação e Saúde. Rio de Janeiro, vol.18, n. 3, janeiro, 2020. Disponível em: <https://www.scielo.br/scielo.php?script=sci_arttext \&pid=S1981-

$77462020000300302 \&$ Ing=pt\&nrm=iso\&tlng=pt. >. Acesso em: 15 mai. 2020.

CARVALHO, I. C. M. "El La Nave Vá": Fellini, pandemia e a vida nua. In: CASTRO, D.; DAL SENO, D.; POCHMANN, M. (Org.). Capitalismo e a COVID-19: um debate urgente. São Paulo: ABET, 2020. Disponível em: <http://abet-trabalho.org.br/wp-content/uploads/2020/05/LIVRO.CapitalismoxCovid19.pdf>. Acesso em: 04 mai. 2020.

CAVALCANTE, G. M. M.; PRÉDES, R. A precarização do trabalho e das políticas sociais na sociedade capitalista: fundamentos da precarização do trabalho do assistente social. Libertas, Juiz de Fora, v.10, n.1, p. 1 - 24, jan./jun., 2010. Disponível em: <https://periodicos.ufjf.br/ index.php/libertas/article/view/18195>. Acesso em 25 abr. 2020.

\section{CONSELHO FEDERAL DE SERVIÇO SOCIAL - CFESS. Nota de Orienta-} ções sobre exercício profissional diante da pandemia de COVID-19. 2020. Disponível em: <http://www.cfess.org.br/visualizar/noticia/ cod/1679>. Acesso em: 01 set. 2020.

DIAS, M. T. G. Processos de coordenação e organização da rede de saúde mental e da assistência social na atenção em saúde mental, com destaque ao usuário de álcool e outras drogas, nos municípios da Região Metropolitana do estado do Rio Grande do Sul. Relatório de Pesquisa. Porto Alegre: UFRGS, CNPq, 2017.

. Os profissionais na intersetorialidade para a atenção à saúde e a proteção social: uma revisão narrativa. Sociedade em Debate. Pelotas, v. 24, n. 01, p. 22-40, jan./abr. 2018. 
FUNDAÇÃO INSTITUTO OSWALDO CRUZ - FIOCRUZ. Pesquisa nacional sobre o uso de crack: quem são os usuários de crack e/ou similares do Brasil? quantos são nas capitais brasileiras. Bastos, Francisco Inácio; Bertoni, Neilane (Org.). Rio de Janeiro: ICICT/FIOCRUZ, 2014. Disponível em: <https://programadrogas.fiocruz.br/publicacoes/livros/5>. Acesso em: 04 set. 2020.

. III Levantamento nacional sobre uso de drogas pela população brasileira. Bastos Francisco Inácio (Coordenador). Rio de Janeiro: ICICT/FIOCRUZ, 2017. Disponível em: <https://www.arca.fiocruz.br/ handle/icict/34614>. Acesso em: 04 set. 2020.

. Centro de Estudos e Pesquisas em Emergências e Desastres em Saúde (CEPEDES). Saúde mental e atenção psicossocial na pandemia da COVID-19. Recomendações gerais. NOAL, D. S.; DAMÁSIO, F. (coordenadoras). Curso de Saúde Mental e Atenção Psicossocial em Situação de Pandemia. Rio de Janeiro: FIOCRUZ, 2020. Disponível em: <https://portal.fiocruz.br/video/curso-de-saude-mental-e-atencao-psicossocial-em-situacao-de-pandemia.>. Acesso em: 23 jun. 2020.

FRENTE PELA VIDA. Plano nacional de enfrentamento à pandemia da COVID-19. Versão 03/07/2020. Disponível em: <https://frentepelavida.org.br/>. Acesso em: 03 jul. 2020.

GUERRA, Y. A. D. A instrumentalidade do Serviço Social. São Paulo: Cortez, 1995.

; i et al. Atribuições, competências, demandas e requisições: o trabalho do assistente social em debate. Anais. XV ENPESS, 2016. Disponível em:_http://www.abepss.org.br/arquivos/anexos/guerra-eoutros-201804131237474299190.pdf. Acesso em 02/10/2019>. Acesso em: 02 set. 2020.

HARVEY, D. Política anticapitalista em tempos de coronavírus. Blog da Boitempo. 24 março de 2020. Disponível em: <https://blogdaboitempo.com.br/2020/03/24/david-harvey-politica-anticapitalista-emtempos-de-coronavirus/>. Acesso em: 06 set. 2020.

HONE, T. et al. Effect of economic recession and impact of health and social protection expenditures on adult mortality: a longitudinal 
analysis of 5565 Brazilian municipalities. The Lancet. vol 7, issue 11, november, 2019. Disponível em: <https://www.thelancet.com/action/showPdf?pii=S2214-109X\%2819\%2930409-7>. Acesso em: 17 abr. 2020.

IAMAMOTO, M. V. Renovação e conservadorismo no Serviço Social: ensaios críticos. São Paulo: Cortez, 1992.

. O Serviço Social na contemporaneidade: trabalho e formação profissional. 9 ed. São Paulo: Cortez, 2005.

. 80 anos do Serviço Social no Brasil: a certeza na frente, a história na mão. Serviço Social \& Sociedade, São Paulo, n. 128, p. 13-38, jan./abr. 2017. Disponível em: <http://www.scielo.br/scielo.php? pid $=$ S0101-66282017000100013\&script $=$ sci_abstract $\&$ tlng $=p t>$. Aces so em: 22 jan. 2018.

INOJOSA, R. M. Intersetorialidade e a configuração de um novo paradigma organizacional. Revista de Administração Pública, Rio de Janeiro, v. 32, n. 2, p. 35-48, mar., 1998. Disponível em: <http://bibliotecadigital.fgv.br/ojs/index.php/rap/article/view/7698>. Acesso em: 12 jan. 2017.

INSTITUTO BRASILEIRO DE GEOGRAGIA E ESTATÍ́STICA - IBGE. Agência de notícias. 2020. Disponível em: <https://agenciadenoticias.ibge.gov.br/agencia-noticias/2012-agencia-de-noticias/noticias/28480-desemprego-sobe-para-13-3-no-2-trimestre-com-reducao-recorde-deocupados>. Acesso em: 21 abr. 2020.

KONICZ, T. Crise do coronavírus: o colapso iminente. Blog da Boitempo. 26 de março de 2020. Disponível em: <https://blogdaboitempo.com.br/2020/04/03/crise-do-coronavirus-o-colapso-iminente/>. Acesso em: 24 abr. 2020.

LOPES, M. H. C.; RIZZOTTI, M. L. A. COVID19 e proteção social: a contribuição do Sistema Único de Assistência Social - SUAS. In: CASTRO, D.; DAL SENO, D.; POCHMANN, M. (Org.). Capitalismo e a COVID-19: um debate urgente. São Paulo: ABET, 2020. Disponível em: <http:// abet-trabalho.org.br/wp-content/uploads/2020/05/LIVRO.CapitalismoxCovid19.pdf>. Acesso em: 04 mai. 2020. 
MARX, K. Manuscritos econômico-filosóficos. Tradução Artur Mourão. Lisboa: Edições 70, 1975.

.; ENGELS, F. A ideologia alemã. Tradução Luis Claudio de Castro e Costa. São Paulo: Martins e Fontes, 2002.

MATOS, M. C. A pandemia do coronavírus (COVID-19) e o trabalho de assistentes sociais na saúde. Boletim-COFI: Plantão Coronavírus (CRESS-ES), Vitória, Espírito Santo, n. 2, abr. 2020. Disponível em: <http://www.cress-es.org.br/wp-content/uploads/2020/04/Artigo-Apandemia-do-coronav\%C3\%ADrus-COVID-19-e-o-trabalho-de-assistentes-sociais-na-sa\%C3\%BAde-2.pdf> . Acesso em: 16 abr. 2020.

NAVARRO, $V$. The consequences of neoliberalism in the current pandemic. International Journal of Health Services, v. 50, n. 3, p. 271275, jul., 2020. Disponível em:< https://journals.sagepub.com/doi/ 10.1177/0020731420925449>. Acesso em: 21 jul. 2020.

ORGANIZAÇÃO DAS NAÇÕES UNIDAS - ONU. COVID-19 and the need for action on mental health. 13 de maio de 2020. Disponível em:< https://www.un.org/sites/un2.un.org/files/un_policy_briefcovid_and_mental_health_final.pdf>. Acesso em: 28 ago. 2020.

ORGANIZAÇÃO PAN-AMERICANA DA SAÚDE - OPAS Brasil. OMS afirma que COVID-19 é agora caracterizada como pandemia. 11 de março de 2020. Disponível em: <https://www.paho.org/bra/index.php? option=com_content\&view=article\&id=6120:oms-afirma-que-covid19-e-agora-caracterizada-como-pandemia\&Itemid=812>. Acesso em: 8 abr. 2020.

\section{PANOZZO, V. M. O trabalho do assistente social nos Centros de} Atenção Psicossocial (CAPS) da região metropolitana de Porto Alegre. 2009. 189 f. Tese (Doutorado em Serviço Social). Pontifícia Universidade Católica do Rio Grande do Sul, Porto Alegre, 2009.

PINHEIRO, L.; TOKARSKI, C.; VASCONCELOS, M. Vulnerabilidades das trabalhadoras domésticas no contexto da pandemia de COVID-19 no Brasil. Nota Técnica 75. Brasília: IPEA, ONU Mulheres, junho de 2020. Disponível em:< http://www.onumulheres.org.br/wp-content/uploads/2020/06/213247_NT_Disoc-N_75_web.pdf>. Acesso em: 28 jul. 2020. 
PRAUN, L. A espiral da destruição: legado neoliberal, pandemia e precarização do trabalho. Trabalho, Educação e Saúde, v. 18, n. 3, 2020, e00297129. Disponível em: <https://www.scielo.br/pdf/tes/ v18n3/0102-6909-tes-18-3-e00297129.pdf>. Acesso em: 15 mai. 2020.

PRATES, J. C.; REIDEL, T.; ORTH, T. O trabalho do/a assistente social no Brasil: desafios político-pedagógicos diante de uma conjuntura recessiva e neoconservadora. ConCienciaSocial. Revista digital de Trabajo Social. v. 3, n. 6, 2020. Disponível em: <https://revistas.unc.edu.ar/index.php/ConCienciaSocial/>. Acesso em: 07 set. 2020.

RAICHELIS, R. Serviço Social: trabalho e profissão na trama do capitalismo contemporâneo. In: RAICHELIS, R.; VICENTE, D.; ALBUQUERQUE, V. (Org.) A nova morfologia do trabalho no Serviço Social. São Paulo: Cortez, 2018.

ROSE, N. et al. The social underpinnings of mental distress in the time of COVID-19 - time for urgent action. Wellcome Open Research. 2020. Disponível em: <https://doi.org/10.12688/WELLCOMEOPENRES.16123.1>. Acesso em: 21 ago. 2020.

VIEIRA, E. A. Políticas sociais e direitos sociais no Brasil. São Paulo: Comunicação e Educação, 1997.

YAZBEK, M. C. Fundamentos históricos e teórico-metodológicos e tendências contemporâneas no Serviço Social. In: GUERRA, Y. A. D. et al. (Org.). Serviço Social e seus fundamentos: conhecimento e crítica. Campinas: Papel Social, 2018. 